\title{
Impact of activation cross-section uncertainties on the tritium production in the HFTM specimen cells
}

\author{
O. Cabellos ${ }^{\text {a,* }}$, A. Klix ${ }^{\text {b }}$, U. Fischer ${ }^{\text {b }}$, N. Garcia-Herranz ${ }^{\text {a }}$, J. Sanz ${ }^{\text {a,c }}$, S. Simakov ${ }^{\text {b }}$ \\ a Institute of Nuclear Fusion, Universidad Politécnica de Madrid, Madrid, Spain \\ 'Institute for Reactor Safety, Forschungszentrum Karlsruhe, Germany \\ ${ }^{\mathrm{C}}$ Departamento de Ingeniería Energética, UNED, Madrid, Spain
}

\section{A R T I C L E I N F O}

Article history:

Available online $\mathrm{xxxx}$

\begin{abstract}
A B S T R A C T
The prediction of the tritium production is required for handling procedures of samples, safety \& maintenance and licensing of the International Fusion Materials Irradiation Facility (IFMIF). A comparison of the evaluated tritium production cross-sections with available experimental data from the EXFOR data base has shown insufficient validation. And significant discrepancies in evaluated cross-section libraries, including lack of tritium production reactions for some important elements, were found.

Here, we have addressed an uncertainty analysis to draw conclusions on the reliability of the tritium prediction under the potential impact of activation cross-section uncertainties. We conclude that there is not sufficient experimental validation of the evaluated tritium production cross-sections, especially for iron and sodium. Therefore a dedicated experimental validation program for those elements should be desirable.
\end{abstract}

\section{Introduction}

The estimation of the tritium production in the High Flux Test Module (HFTM) is needed in order to define the appropriated handling, licensing and maintenance procedures [1].

The HFTM consists of twelve rigs positioned in a container subdivided in four different compartments made of austenitic steel [2]. Each compartment houses three capsules. The rigs contain the irradiation capsules with miniaturized material specimens. They can be positioned at any container position. A gap filled with stagnant helium at low pressure acts as thermal insulation between the rig and capsule walls. Capsules, rigs and containers are cooled by low pressure helium gas. The specimens in the capsules are embedded in stagnant liquid NaK alloy to guarantee a defined heat transfer. For this study [1], three specimen cell types having different initial compositions are considered (see Table 1). The position of the twelve rigs of the HFTM is shown in Table 2.

In a previous work [1], the tritium production was calculated for each test rig in the HFTM using the activation data from both IEAF2001 intermediate energy library and EAF-2007 library. The activation calculations were done with FISPACT-2007 code. The results showed large differences for the total tritium prediction: 23.4 Ci/fpy with IEAF-2001 and $11.2 \mathrm{Ci} / \mathrm{fpy}$ with EAF-2007. In general, it was found that the contribution from $\mathrm{NaK}$ is lightly higher using
EAF-2007, but the contribution from other metals, and mainly from $\mathrm{Fe}$, is much more significant using IEAF-2001. The main reason of the discrepancies is the large differences in $\mathrm{Na}^{23}$ and $\mathrm{Fe}^{54}$ tritium production cross-sections between IEAF-2001 and EAF-2007 (see Figs. 1 and 2 ).

Due to those significant discrepancies, the purpose of this work is: (i) to perform a sensitivity/uncertainty analysis to assess the impact of activation cross-section uncertainties on the tritium prediction, (ii) to identify the most relevant reaction channels, and (iii) to priorize the data improvement needs.

\section{Methodology for tritium prediction}

In the activation calculations a constant neutron environment is assumed for 1 year of irradiation period ( $1 \mathrm{fpy}$ ). The McDeLicious code [3] has been used to compute the neutron flux intensity $\left(\mathrm{n} / \mathrm{cm}^{2} \mathrm{~s}\right)$ and neutron spectrum for the twelve rigs. For these rigs, the flux of neutrons having energies above $1 \mathrm{MeV}$ is $\sim 97 \%$. Details are given in Table 2, where the definition of three neutron zones (A, B and C) with similar characteristics of neutron irradiation is also illustrated.

In this paper, activation calculations are performed with ACAB-2008 code [3] and the activation cross-section data library EAF-2007. As expected, we obtain identical results to the ones reported using FISPACT-2007 [2].

We have evaluated the main contributions to the tritium production due to the initial isotopes in the rigs, and results are in Table 3. In rig 2, the largest contribution is from Fe. In rig 1 
Table 1

Initial composition (in \% atom fraction) for the three test rigs.

\begin{tabular}{lccc}
\hline Element & Rig 1 & Rig 2 & Rig 3 \\
\hline $\mathrm{Cr}$ & 7.1 & 9.3 & 7.9 \\
$\mathrm{C}$ & 0.40 & 0.5 & 0.4 \\
$\mathrm{Mn}$ & 0.30 & 0.39 & 0.33 \\
$\mathrm{~V}$ & 0.26 & 0.21 & 0.18 \\
$\mathrm{~W}$ & 0.22 & 0.29 & 0.25 \\
$\mathrm{Ta}$ & 0.016 & 0.021 & 0.018 \\
$\mathrm{Fe}$ & 65.50 & 86.0 & 73.4 \\
$\mathrm{Na}$ & 18.0 & 2.3 & 12.0 \\
$\mathrm{~K}$ & 8.30 & 1.0 & 5.5 \\
\hline
\end{tabular}

Table 2

Neutron flux $\left(\mathrm{n} / \mathrm{cm}^{2} \mathrm{~s}\right)$ and average neutron energy $(\mathrm{MeV})$. The position of the rigs is indicated in the container. The three neutron zones (A, B and C) are also illustrated.

\begin{tabular}{|c|c|c|c|c|c|c|c|c|}
\hline & $\begin{array}{l}\left(\mathrm{n} / \mathrm{cm}^{2} \mathrm{~s}\right) \\
(\mathrm{MeV})\end{array}$ & Rig\# & $\begin{array}{l}\left(\mathrm{n} / \mathrm{cm}^{2} \mathrm{~s}\right) \\
(\mathrm{MeV})\end{array}$ & Rig\# & $\begin{array}{l}\left(\mathrm{n} / \mathrm{cm}^{2} \mathrm{~s}\right) \\
(\mathrm{MeV})\end{array}$ & Rig\# & $\begin{array}{l}\left(\mathrm{n} / \mathrm{cm}^{2} \mathrm{~s}\right) \\
(\mathrm{MeV})\end{array}$ & Rig\# \\
\hline Zone C & $\begin{array}{l}4.07 \mathrm{E}+14 \\
5.29\end{array}$ & R1 & $\begin{array}{l}4.79 \mathrm{E}+14 \\
5.48\end{array}$ & $\mathrm{R} 2$ & $\begin{array}{l}4.71 \mathrm{E}+14 \\
5.51\end{array}$ & R3 & $\begin{array}{l}4.05 \mathrm{E}+14 \\
5.29\end{array}$ & R1 \\
\hline Zone B & $\begin{array}{l}5.15 \mathrm{E}+14 \\
5.63\end{array}$ & R2 & $\begin{array}{l}5.92 \mathrm{E}+14 \\
5.77\end{array}$ & R3 & $\begin{array}{l}5.81 \mathrm{E}+14 \\
5.72\end{array}$ & $\mathrm{R} 1$ & $\begin{array}{l}5.13 \mathrm{E}+14 \\
5.63\end{array}$ & $\mathrm{R} 2$ \\
\hline Zone A & $\begin{array}{l}6.77 \mathrm{E}+14 \\
5.96 \\
\text { Lithium lo }\end{array}$ & $\begin{array}{l}\text { R3 } \\
\text { op }\end{array}$ & $\begin{array}{l}7.65 \mathrm{E}+14 \\
5.89\end{array}$ & R1 & $\begin{array}{l}7.73 \mathrm{E}+14 \\
5.77\end{array}$ & $\mathrm{R} 2$ & $\begin{array}{l}6.77 \mathrm{E}+14 \\
5.96\end{array}$ & R3 \\
\hline
\end{tabular}

and rig 3, contributions from $\mathrm{Na}$ and $\mathrm{K}$ (coolant elements) are as important as Fe. The contribution due to $\mathrm{Cr}$ is less than $5 \%$. In addition, we have observed that those values are similar in zones A, B and C. Therefore, we can conclude that such contributions only depend on the initial composition of the rig, being negligible the influence of the neutron spectrum.

Tritium production for each rig with the best-estimate crosssection data library EAF2007 is shown in Table 4, ranging from 0.6 to $1.3 \mathrm{Ci} /$ fpy. In addition, the main reactions for tritium prediction were determined with CHAINS code (module of the ACAB package to perform computational pathways analyses). It has been found that for $\mathrm{Fe}^{56}$ and $\mathrm{Na}^{23}$, many reactions contribute to tritium production. However, only four reactions have a contribution above $10 \%$ : (i) $\mathrm{Na}^{23}(\mathrm{n}, \mathrm{t})$ and $\mathrm{Na}^{23}(\mathrm{n}, \mathrm{nt})$, with a contribution of $60.3 \%$ and $10.1 \%$, respectively, and (ii) $\mathrm{Fe}^{56}(\mathrm{n}, \mathrm{t})$ and $\mathrm{Fe}^{56}(\mathrm{n}, \mathrm{nt})$, with $51.4 \%$ and $11.4 \%$, respectively.

To complete the analysis performed in Ref. [1] about the differences between EAF2007 and IEAF2001 cross-section data, we have investigated the tritium production $(\mathrm{n}, \mathrm{Xt})$ cross-sections from other evaluated nuclear data libraries: ENDF/B-VII, JEFF-3.1 and JENDL-He. Figs. 1 and 2 show tritium production cross-section ( $\mathrm{n}, \mathrm{Xt})$ and main partial reactions such as $(\mathrm{n}, \mathrm{t}),(\mathrm{n}, \mathrm{nt}),(\mathrm{n}, \mathrm{npt})$ and $\left(\mathrm{n}, \mathrm{t} \alpha\right.$ ) for $\mathrm{Fe}^{54}$ and $\mathrm{Na}^{23}$. The following remarks can be made: (i) For $\mathrm{Fe}^{54}$, a large discrepancy can be seen between IEAF2001 and the other evaluated data libraries. (ii) For $\mathrm{Na}^{23}$ many evaluated data libraries do not contain tritium producing reactions, such as ENDF/B-VII, and a large discrepancy between the different libraries is also found. In the case of $\mathrm{Fe}^{56}$ the differences among the evaluated libraries are not so remarkable.

\section{Uncertainty analysis on the tritium production in the HFTM specimen cells}

$\mathrm{ACAB}$ code is able to perform a sensitivity/uncertainty analysis $[4,5]$.

Firstly, to address the uncertainty problem in a reliable way, we have applied a Monte Carlo method (implemented in our inventory $\mathrm{ACAB}$ code) based on a simultaneous random sampling of all the cross-section probability density functions. We make use of the EAF-2007/UN uncertainty library to perform this job.

In Table 4, we present the nominal value calculated without uncertainties, as well as the mean value and the standard deviation predicted with the Monte Carlo method. Here, the results are obtained for a 1000 history-sampling. It is worth pointing out that: (i) the mean of the 1000 values of the total tritium production in all rigs ( $13.7 \mathrm{Ci} / \mathrm{fpy})$ is slightly higher to that obtained using the nominal cross-section values without uncertainties (11.2 Ci/fpy); (ii) relative errors up to $51 \%$ in tritium prediction can be found in rig 2 ; (iii) similar relative errors for the same rigs positioned in dif-

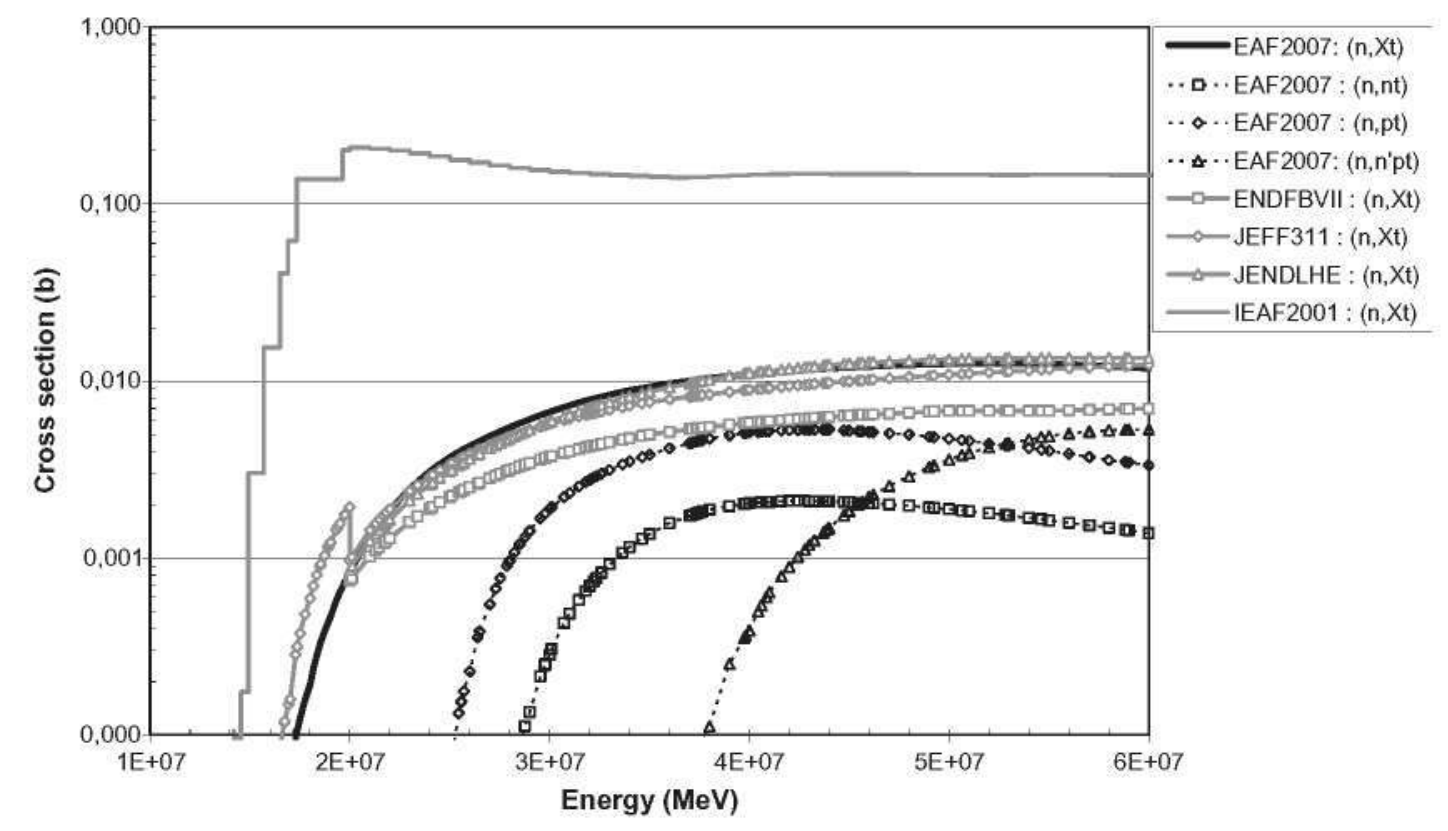

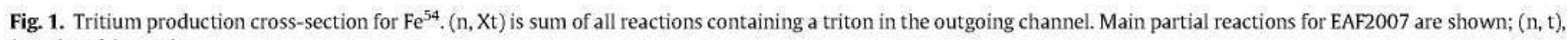
$(\mathrm{n}, \mathrm{nt})$ and $(\mathrm{n}, \mathrm{npt})$. 


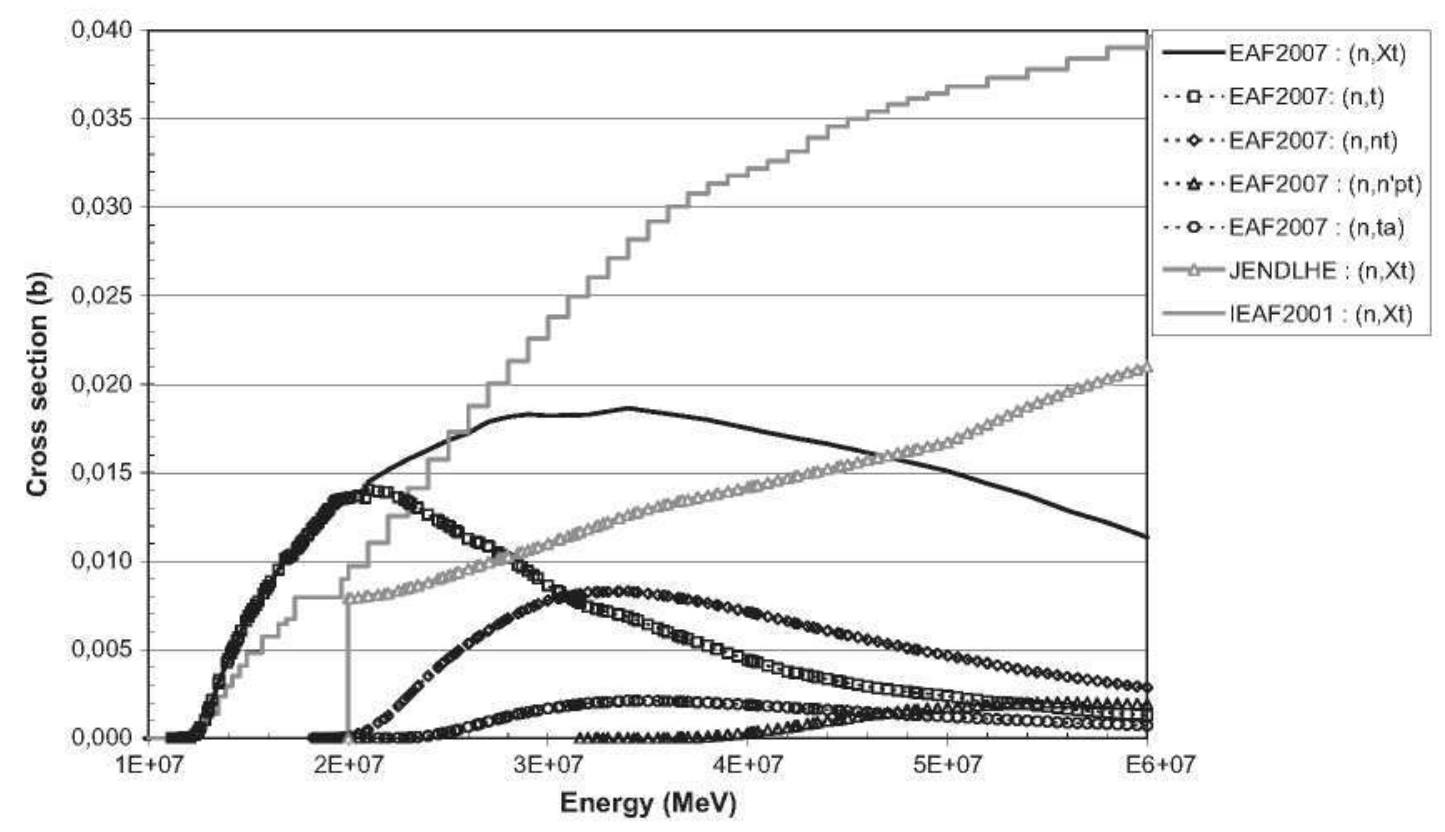

Fig. 2. Tritium production cross-section for $\mathrm{Na}^{23} .(\mathrm{n}, \mathrm{Xt})$ is sum of all reactions containing a triton in the outgoing channel, Main partial reactions for EAF2007 are shown: $(\mathrm{n}, \mathrm{t}),(\mathrm{n}, \mathrm{nt}),(\mathrm{n}, \mathrm{ta})$ and $(\mathrm{n}, \mathrm{npt})$.

Table 3

List of initial isotopes with a contribution (in \%) to the tritium production greater than $1 \%$.

\begin{tabular}{lrrr}
\hline Isotope & Rig 1 & Rig 2 & Rig 3 \\
\hline $\mathrm{Na}^{23}$ & 45.7 & 8.7 & 34.6 \\
$\mathrm{~K}^{39}$ & 8.0 & 1.4 & 6.1 \\
$\mathrm{Cr}^{52}$ & 2.2 & 4.3 & 2.8 \\
$\mathrm{Cr}^{53}$ & 0.5 & 1.1 & 0.7 \\
$\mathrm{Fe}^{54}$ & 1.5 & 3.0 & 2.0 \\
$\mathrm{Fe}^{56}$ & 38.2 & 76.5 & 50.2 \\
$\mathrm{Fe}^{57}$ & 1.2 & 2.4 & 1.6 \\
\hline
\end{tabular}

Table 4

Tritium production: nominal value ( $\mathrm{C} / \mathrm{fppy}$ ) calculated with the best-estimate crosssection data library EAF2007 and mean value (Ci/fpy) and standard deviation (Ci/fpy) calculated with the EAF2007/UN library using the Monte Carlo method.

\begin{tabular}{|c|c|c|c|c|c|c|c|}
\hline $\begin{array}{l}\text { Nominal } \\
\text { value } \\
\text { (Ci/fpy) } \\
\text { Mean } \pm \text { s.d. } \\
\text { (Ci/fpy) }\end{array}$ & Rig\# & $\begin{array}{l}\text { Nominal } \\
\text { value } \\
\text { (Ci/fpy) } \\
\text { Mean } \pm \text { s.d. } \\
\text { (Ci/fpy) }\end{array}$ & Rig\# & $\begin{array}{l}\text { Nominal } \\
\text { value } \\
\text { (Ci/fpy) } \\
\text { Mean } \pm \text { s.d. } \\
\text { (Ci/fpy) }\end{array}$ & Rig\# & $\begin{array}{l}\text { Nominal } \\
\text { value } \\
\text { (Ci/fpy) } \\
\text { Mean } \pm \text { s.d. } \\
\text { (Ci/fpy) }\end{array}$ & Rig\# \\
\hline 0.6 & $\mathrm{R} 1$ & 0.8 & $\mathrm{R} 2$ & 0.7 & R3 & 0.6 & R1 \\
\hline $0.7 \pm 0.3$ & & $1.0 \pm 0.5$ & & $0.9 \pm 0.3$ & & $0.7 \pm 0.3$ & \\
\hline 0.9 & $\mathrm{R} 2$ & 1.0 & R3 & 0.9 & R1 & 0.9 & R2 \\
\hline $1.1 \pm 0.6$ & & $1.2 \pm 0.5$ & & $1.1 \pm 0.4$ & & $1.1 \pm 0.6$ & \\
\hline 1.1 & R3 & 1.2 & R1 & 1.3 & $\mathrm{R} 2$ & 1.1 & R3 \\
\hline $1.4 \pm 0.5$ & & $1.4 \pm 0.5$ & & $1.6 \pm 0.9$ & & $1.4 \pm 0.5$ & \\
\hline
\end{tabular}

ferent location in the container are obtained; (iv) the histogram of the 1000 values obtained for tritium prediction fit to a long tail lognormal distribution.

To easily assess the contribution of each source-element to the uncertainty in the tritium generation, an element-by-element analysis has been performed. We have calculated the tritium production (Ci/fpy) due to an initial mass of $1000 \mathrm{~g}$ for each initial element, and we have averaged the computed values in the three zones A, B and C. Results are illustrated in Table 5. It can be seen that: (i) Na is the element with the largest generation of tritium, (ii) $\mathrm{V}$ is the element with the largest relative error in the prediction of tritium ( $\sim 120 \%$ ), and (iii) $\mathrm{Fe}$ and $\mathrm{Na}$ have relative errors of $\sim 56 \%$ and $\sim 70 \%$, respectively.

These element-by-element results can be used to predict the tritium performance of any material irradiated in these neutron environments using Eq. (1).

$A=\sum_{i=F e, N a, \ldots} w_{i} \cdot A_{i}$

where $A$ is the total tritium production, $w_{i}$ is mass weight fraction of element $i$, and $A_{i}$ is the tritium production of element $i$ per mass unit.

Since these $A_{i}$ values are not correlated, the variance of $A$ can be calculated using Eq. (2). With these values, we can determine the total relative error and the main contribution to the total error due to each element in the different rigs. We have predicted that such errors only depend on the initial composition of the rig, being negligible the influence of the neutron spectrum. In Table 6, total relative error for the three specimen cell types were found, ranging from $38 \%$ to $51 \%$. It can be seen that Fe and Na are the main sources of error.

$\operatorname{var}(A)=\sum_{i=F e, N a, \ldots} w_{i}^{2} \cdot \operatorname{var}\left(A_{i}\right)$

Secondly, we have performed a sensitivity analysis to identify the main cross-sections responsible of the total uncertainty in the tritium prediction. At this respect, we have defined the sensitivity coefficient for the production of tritium $(\mathrm{T})$ due to uncertainty in cross-section $j$ as $\rho_{j T}=\left(\sigma_{j 0} / T_{0}\right)\left[\partial T / \partial \sigma_{j}\right]_{\sigma_{0}}$, where $\sigma_{j 0}$ and $T_{0}$ refers to the corresponding nominal values. This coefficient provides a direct measure of the cross-section $j$ importance to the tritium generation. It can be used in conjunction with the cross-section uncertainties to determine the cross-sections that contribute most significantly to the uncertainty in the tritium prediction. In Table 7 , column 2 provides the computed sensitivity coefficients for the main reactions identified and column 3 shows the uncertainty (relative error, 4 ) from EAF2007/UN. Finally, column 4 illustrates the calculated index $\rho_{i r} * \Delta$ that can be used to rank cross-sections 
Table 5

Tritium production and standard deviation (in Ciffpy) due to an initial mass of $1000 \mathrm{~g}$ for each initial element used in HFTM rigs in the three zones $\mathrm{A}_{\mathrm{r}} \mathrm{B}$ and $\mathrm{C}$.

\begin{tabular}{|c|c|c|c|c|c|c|c|c|c|}
\hline Zone & $\mathrm{Cr}$ & C & $\mathrm{Fe}$ & K & Mn & $\mathrm{Na}$ & $\mathrm{Ta}$ & V & $W$ \\
\hline A & $4.2 \pm 2.5$ & $46.2 \pm 10.8$ & $6.0 \pm 3.4$ & $14.0 \pm 6.4$ & $9.6 \pm 7.6$ & $57.2 \pm 40.8$ & $1.8 \pm 1.4$ & $6.1 \pm 7.4$ & $1.6 \pm 0.9$ \\
\hline B & $2.8 \pm 1.6$ & $31.1 \pm 7.2$ & $4.1 \pm 2.3$ & $9.6 \pm 4.3$ & $6.5 \pm 5.1$ & $39.2 \pm 27.5$ & $1.3 \pm 1.0$ & $4.1 \pm 4.9$ & $1.1 \pm 0.6$ \\
\hline$C$ & $2.4 \pm 1.4$ & $26.3 \pm 6.1$ & $3.5 \pm 2.0$ & $8.1 \pm 3.6$ & $5.5 \pm 4.3$ & $33.3 \pm 23.2$ & $1.1 \pm 0.8$ & $3.5 \pm 4.1$ & $0.9 \pm 0.5$ \\
\hline
\end{tabular}

Table 6

Total relative error for the three specimen cell types, and contribution for the initial elements (in \%) for the total variance.

\begin{tabular}{|c|c|c|c|c|c|c|c|c|c|c|}
\hline \multirow[t]{2}{*}{ Rig\# } & \multirow[t]{2}{*}{ Total relative error $(\%)$} & \multicolumn{9}{|c|}{ Contribution for the initial elements (in \%) } \\
\hline & & $\mathrm{Cr}$ & $c$ & $\mathrm{Fe}$ & $\mathrm{K}$ & $\mathrm{Mn}$ & $\mathrm{Na}$ & $\mathrm{Ta}$ & $v$ & $w$ \\
\hline R1 & 37.9 & 0.2 & 0.0 & 39.4 & 0.9 & 0.0 & 59.6 & 0.0 & 0.0 & 0.0 \\
\hline $\mathrm{R} 2$ & 51.0 & 0.5 & 0.0 & 97.6 & 0.0 & 0.0 & 1.8 & 0.0 & 0.0 & 0.0 \\
\hline R3 & 40.0 & 0.3 & 0.0 & 58.5 & 0.6 & 0.0 & 40.6 & 0.0 & 0.0 & 0.0 \\
\hline
\end{tabular}

\section{Table 7}

Uncertainty and sensitivity information for cross-sections that contribute most to the uncertainty in the tritium prediction. $\rho_{\mu}$ is the sensitivity coefficient for the tritium production from the activation of an isotope after 1 fpy. $\Delta$ is the corresponding relative error.

\begin{tabular}{llrl}
\hline Isotope & $\rho_{j \mathrm{~T}}$ & $\Delta(\%)$ & $\rho_{j \mathrm{IT}} * \boldsymbol{\Delta}$ \\
\hline $\mathrm{Fe}^{56}(\mathrm{n}, \mathrm{nt})$ & 0.07 & 133.3 & 9.03 \\
$\mathrm{Na}^{23}(\mathrm{n}, \mathrm{nt})$ & 0.06 & 133.3 & 8.39 \\
$\mathrm{Na}^{23}(\mathrm{n}, \mathrm{t})$ & 0.38 & 4.3 & 1.86 \\
$\mathrm{Fe}^{56}(\mathrm{n}, \mathrm{t})$ & 0.31 & 4.3 & 1.32 \\
$\mathrm{~K}^{39}(\mathrm{n}, \mathrm{nt})$ & 0.008 & 133.3 & 1.08 \\
$\mathrm{Na}^{23}(\mathrm{n}, \mathrm{t}(\mathrm{x})$ & 0.01 & 66.7 & 0.68 \\
$\mathrm{Cr}^{52}(\mathrm{n}, \mathrm{nt})$ & 0.005 & 133.3 & 0.64 \\
\hline
\end{tabular}

inducing the highest uncertainties in the tritium prediction: $\mathrm{Na}^{23}$ and $\mathrm{Fe}^{56}$ (n, nt) reactions.

\section{Conclusions}

The uncertainty in the prediction of tritium in the HFTM is relevant to define the appropriated handling, licensing and maintenance procedures in IFMIF. In this regard, the estimation of the tritium production in the HFTM has been performed using different activation codes and evaluated nuclear data libraries. This prediction has shown to be greatly influenced by the activation cross-section data. EAF2007 has shown a good agreement when existing ENDF/B tritium production cross-sections, and large differences between EAF2007 and IEAF2001 were found for the most important $(n, X t)$ reactions in $\mathrm{Fe}^{54}$ and $\mathrm{Na}^{23}$. There is still a significant lack of experimental data, and uncertainties of several cross-sections remain high.

In the present work, based on the Monte Carlo method using $A C A B$ code, the induced tritium prediction was calculated as a mean value and a standard error. And, the uncertainty estimates are based on EAF2007/UN data library. It was found that the tritium uncertainty is significant for all the analyzed elements. At this respect. Fe and $\mathrm{Na}$ exhibit uncertainties in the tritjum response with a relevant practical significance in order to assess the acceptability of tritium generation in JFMJF. $\mathrm{Fe}^{56}(\mathbf{n}, \mathbf{n t})$ and $\mathrm{Na}^{23}(\mathbf{n}, \mathbf{n t})$ were identified as the most important reactions that contribute to the total uncertainty in the tritium prediction having relative errors of $\sim 133 \%$.

It should be emphasized that there is not sufficient experimental validation of the evaluated tritium production cross-sections especially for Fe and $\mathrm{Na}$. Therefore a dedicated experimental validation program for those elements should be desirable.

\section{Acknowledgement}

This work has been performed under Plan Nacional ]+D+[ 20082011, ENE2008-06403-C06-06/FTN and C06-02/FTN, Ministerio de Ciencia e Innovación, Spain, and EU keep-in touch Program on IFE.

\section{References}

[1] A. Klix, 5. Simakov, U. Fischer, Estimation of the tritium production in the HFTM specimen cells, EFFDOC-1054, 2008.

[2] V. Heinzel et al., The IFMIF Test Cell - Design and Neutronics Overview, FT/P724. 20th IAEA Fusion Energy Conference, 2004.

[3] S.P. Simakov, U. Fischer, H. Heinzel, U. von Moellendorff, International Fusion Material Irradiation Facility (IFMIF): Neutron Source Term Simulation and Neutronics Analyses of the High Flux Test Module, Report FZKA 6743, Karlsruhe, July 2002.

[4] J. Sanz, O. Cabellos, N. Garcia-Herranz, ACAB-2008, Inventory Code for Nuclear Applications: User's Manual V. 2008, NEA-1839, 2009.

[5] 0. Cabellos. N. García-Herranz. J. Sanz, B. Otero. J. Nucl. Mater. 386-388 (2009) 908. 